\title{
$\omega$-Conotoxin Prevents Myelin-evoked Growth Cone Collapse in Neonatal Rat Locus Coeruleus Neurons in vitro
}

\author{
Stephen J. Moorman ${ }^{a}$ and Richard I. Hume \\ Department of Biology, University of Michigan, Ann Arbor, Michigan 48109
}

\begin{abstract}
The response of neonatal rat locus coeruleus neurons to contact with myelin extracts prepared from the CNS and PNS was examined. The growth cones of these neurons collapsed following contact with central myelin, but continued to elongate on contact with peripheral myelin. Central myelin elicited an increase in the intracellular free calcium concentration in these growth cones, while peripheral myelin did not. This increase appeared to require transmembrane calcium flux, since it was blocked by extracellular EGTA, and also by extracellular cobalt. These neurons express $\mathrm{N}$ - and L-type calcium channels. Exposure to $5 \mu \mathrm{M} \omega$-conotoxin GVIA, a specific blocker of $\mathrm{N}$-type channels, prevented both the myelin-evoked increase in growth cone calcium concentration and the collapse of growth cones.
\end{abstract}

[Key words: growth cone, myelin, locus coeruleus neurons, neonatal rat, $\omega$-conotoxin GVIA, calcium channels]

The paths taken by developing or regenerating axons to their appropriate targets are determined by the growth cone. Growth cone behaviors in response to contact with other cells can take several forms, among which are turning, collapse, retraction, fasciculation, and change in growth rate. Each of these behaviors may indicate recognition of particular cells or environmental cues that play a specific role in axon guidance during development. Time-lapse microscopy studies have shown that different types of neurons from newborn rats can respond in different ways to the same extracellular matrix molecules (Caroni and Schwab, 1988b). Similar studies have demonstrated that growth cones can respond with a variety of behaviors to molecules on the cell surfaces of other neurons (Kapfhammer and Raper, 1987). These results suggest that neurons respond in a cell-typespecific manner to environmental signals.

Of particular interest is growth cone collapse because of its potential relevance to both development and regeneration in the vertebrate CNS (see Keynes and Cook, 1992). The failure of neurons to regenerate following injury to the CNS may be due in part to the interaction of the growth cone with molecules present on the surface of oligodendrocytes. (Caroni and Schwab,

\footnotetext{
Received Aug. 11, 1992; revised May 5, 1993; accepted May 11, 1993.

We thank James Walker, Cheryl McCullumsmith, and Xiaopei Huang for helpful discussions, and Tim Hassinger for preparing some of the myelin extract. Part of this work was performed while S.J.M. was on a Young Investigator Fellowship at the Marine Biological Laboratory at Woods Hole. This work was supported by NIH Grant NS 21043 and a grant from the American Paralysis Association.

Correspondence should be addressed to Richard I. Hume, Department of Biology, Natural Science Building, University of Michigan, Ann Arbor, MI 48109.

aPresent address: Department of Anatomy and Cell Biology, Texas College of Osteopathic Medicine, 3500 Camp Bowie Boulevard, Fort Worth, TX 76107.

Copyright (C) 1993 Society for Neuroscience $0270-6474 / 93 / 134727-10 \$ 05.00 / 0$
}

1988b). Tissue culture experiments have demonstrated that CNS myelin and differentiated oligodendrocytes present a nonpermissive, possibly inhibitory substrate for neurite outgrowth and nerve cell adhesion. This effect is mediated by specific membrane proteins present on the surface of these myelin-forming cells and is seen as collapse and retraction of the neuronal growth cone after contact with oligodendrocytes. The same group has reported that antibodies to proteins shown to cause growth cone collapse and retraction in vitro can promote regrowth in vivo (Schnell and Schwab, 1990). These experiments emphasize the importance of understanding the cellular basis of growth cone collapse.

Recent evidence suggests that changes in internal free calcium concentration are involved in regulating neurite outgrowth and growth cone morphology. Calcium channel blockers or removal of extracellular calcium has been reported to inhibit neurite extension in several cell types (see Kater and Mills, 1991). In addition, calcium currents have been identified in growth cones of actively extending neurites, but not in spontaneously inactive growth cones (Anglister et al., 1982). Possible mechanisms by which calcium might alter neurite outgrowth are by acting directly or through a kinase or calmodulin to regulate the behaviors of the cytoskeletal elements that underlie neurite elongation and growth cone motility (Lankford and Letourneau, 1989).

Most studies of the effect of myelin on growth cone motility have used peripheral neurons, because these neurons are easily isolated as pure populations. As noted above, the growth cones of different types of neurons can respond to a common environment in quite different ways. It therefore seemed essential to us to study the effect of myelin on a population of neurons that are relevant to CNS regeneration. In this article we have investigated the mechanisms by which myelin from the CNS triggers the collapse of growth cones of cultured rat brainstem neurons from the region of locus coeruleus. We chose locus coeruleus neurons because successful recovery of function after a spinal cord injury is likely to require regeneration of the processes of neurons whose cell bodies are cranial to the site of the lesion, that is, in the brain or brainstem. A further advantage of studying locus coeruleus neurons is that the noradrenaline produced and released by these neurons has well-defined effects on spinal cord reflexes (Jankowska et al., 1967) and locomotion (Forssberg and Grillner, 1973).

In the experiments reported here, we show that changes in calcium concentration precede the growth cone collapse observed after contact with myelin from the CNS of the adult rat. We also demonstrate that a pharmacological agent that is known to block a specific class of voltage-dependent calcium channels can prevent both the increase in calcium concentration and the collapse of the growth cone following contact with myelin. 


\section{Materials and Methods}

\section{Culture of locus coeruleus neurons}

Neonatal Sprague-Dawley rats, 1-5 d old, were killed by decapitation. The skin and calvaria were removed using fine dissection scissors. The brain and brainstem were removed intact and placed in Puck's solution. All solutions and media had glucose added to bring the total concentration to $6 \% \mathrm{w} / \mathrm{v}$. The brainstem was transected both rostral and caudal to the cerebellum to yield a slice of tissuc that included the region of brainstem that lies immediately ventral to the cerebellum, as well as the entire cerebellum and intact cerebellar peduncles. A small piece of brainstem tissue was then removed from the lateral portion of the floor of the fourth ventricle adjacent to the cerebellar peduncles on both sides. This region of the fetal (Brundin and Strecker, 1991) and neonatal (Masuko et al., 1986) rat brainstem contains primarily the locus coeruleus. Tissue was placed in $0.01 \%$ trypsin (Sigma, type XII-S) in Puck's solution for $24 \mathrm{~min}$ at $36^{\circ} \mathrm{C}$. After enzyme treatment, the tissue was triturated and spun twice at $1000 \mathrm{rpm}$ through 4\% BSA in media, to remove cellular debris. Dissociated cells were plated in modified tissue culture dishes (Honig and Hume, 1986) coated with poly-D-lysine as a substratum (Letourneau, 1975). Cell were grown in F-12 media (GIBCO) containing added glucose $(4.2 \%), 8 \mu \mathrm{g} / \mathrm{ml}$ insulin, $40 \mu \mathrm{g} / \mathrm{ml} \mathrm{con-}$ albumin, $12 \mu \mathrm{g} / \mathrm{ml}$ ascorbic acid, $2 \%$ heat-inactivated horsc scrum, 50 $\mathrm{ng} / \mathrm{ml} 7 \mathrm{~S}-\mathrm{NGF}, 50 \mathrm{U} / \mathrm{ml}$ penicillin, $0.1 \%$ chick embryo extract, and $0.1 \%$ neonatal rat brain extract.

In all of our experiments we only studied large multipolar neurons. Neurons in this group had phase-bright cell bodies averaging $25.6 \mu \mathrm{m}$ $( \pm 3.63, n=20)$ in diameter, and were clearly a separate population from the next largest class of neurons, which averaged $16.3 \mu \mathrm{m}( \pm 1.7$, $n=20$ ) in diameter. Using similar dissection and culture techniques, Masuko et al. (1986) demonstrated that $>98 \%$ of neurons with cell bodies larger than $20 \mu \mathrm{m}$ stained positive for catecholamines. For this reason, we refer to the cells that we studied as locus coeruleus neurons.

\section{Preparation of myelin}

Extracts of CNS myelin were prepared from adult rat spinal cords. Extracts of PNS myelin were prepared from adult rat ischiatic nerve. Both extracts were prepared in the following manner (Norton, 1976).

Step 1: crude fraction isolation. Adult nervous tissue $(4.5-6.0 \mathrm{gm}$, spinal cord or ischiatic nerve) was homogenized in $50 \mathrm{ml}$ of ice-cold $0.35 \mathrm{~m}$ sucrose. After homogenization, the volume was adjusted to 100 $\mathrm{ml}$ with $0.35 \mathrm{M}$ sucrose; $25 \mathrm{ml}$ of homogenate was layered over $25 \mathrm{ml}$ of $0.85 \mathrm{~m}$ sucrose in each of two centrifuge tubes and centrifuged at $48,000 \times g$ for $30 \mathrm{~min}$. The layer of crude myelin that formed at the interface of the two sucrose solutions was collected with a Pasteur pipette.

Step 2: sucrose washout. The combined myelin layers were suspended in $10 \mathrm{~mm}$ HEPES (pH 7.2) in water by homogenization and brought to a final volume of $180 \mathrm{ml}$. This suspension was centrifuged at $48,000 \times$ $g$ for $15 \mathrm{~min}$ and the supernatant discarded.

Step 3: osmotic shock. The myelin pellets were again dispersed in 180 $\mathrm{ml}$ of $10 \mathrm{~mm}$ HEPES in water and centrifuged at $12,000 \times \mathrm{g}$ for 10 min. The supernatant was discarded. This step was repeated twice.

Step 4: purified myelin. The myelin pellet was suspended in $0.35 \mathrm{M}$ sucrose and layered over $0.85 \mathrm{~m}$ sucrose in each of two tubes, and centrifuged as in step 1. The purified myelin was removed from the interface using a Pasteur pipette.

Step 2 was repeated at the end to yield a pellet of myelin in $10 \mathrm{~mm}$ HEPES (pH 7.2) in water. This pellet was aliquoted into $50 \mu \mathrm{l}$ samples and stored at $-70^{\circ} \mathrm{C}$ until used. Immediately prior to use, $75 \mu \mathrm{l}$ of media was added to an aliquot of myelin. The osmolality of the media added to the myelin extract was adjusted with sucrose so that when added to the myelin the final osmolality was $300 \mathrm{mOsm}$. Myelin extract was placed in contact with growth cones by extrusion from a puffer pipette.

For certain experiments, the CNS myelin extract was heat inactivated by maintaining the extract at $100^{\circ} \mathrm{C}$ for $30 \mathrm{~min}$. For other cxpcriments, the CNS myelin extract was treated with $0.02 \%$ trypsin at $37^{\circ} \mathrm{C}$ for 30 min.

In order to test whether the effect evoked by myelin was specific to an extract of nervous tissue, we tried preparing separate extracts of adult rat liver and adult rat kidneys using the same protocol that was used to make the myelin extracts. However, no material was present in the final pellet.

\section{Video microscopy}

We made video microscopic observations of neonatal rat locus coeruleus neurons using an inverted microscope that was modified so that the stage, objectives, and culture dish were maintained at $37^{\circ} \mathrm{C}$. Before the culture dish was placed on the microscope, the normal medium was replaced by medium containing $20 \mathrm{mM}$ HEPES $(\mathrm{pH} 7.3)$ and then preheated mineral oil was placed over the media to prevent evaporation. Using mineral oil allowed access to the cells for myelin application without degradation of either the fluorescent or phase-contrast images. Locus coeruleus neurons were identified by the size of their cell bodies. In the majority of experiments the growth of processes was followed using time-lapse video microscopy of phase contrast images as previously described (Moorman and Hume, 1990).

Growth cone position (the most distal point on the lamellipodia at the leading edge of the growth cone) in relation to two fixed reference points was monitored for 5-10 min before application of myelin extract. The myelin extract was washed off $60 \mathrm{~min}$ after application, and the position of the growth cone in relation to the same reference points was determined. The total surface area of the growth cone excluding the filopodia was also measured before and $60 \mathrm{~min}$ after application of myelin extract. For the purpose of measuring surface area, it was necessary to define the beginning of the growth cone. For cells with extended growth cones the beginning was defincd as the point where the caliber of the neurite began to increase. Using the IMAGE-1 software, the growth cone's outline (excluding any filopodia) was traced and the software was used to calculate the area within the outline. When the growth cone collapsed or retracted, we estimated surface area using the beginning point prior to collapse. A growth cone was scored as having collapsed if the surface area decreased by more than $50 \%$.

To monitor growth cone morphology while the myelin extract was in contact with the growth cone, it was necessary to use fluorescence video microscopy, because the myelin extract degraded phase-contrast images. In these experiments cells were loaded with Fura-2 (see below) and the fluorescence in response to excitation at $380 \mathrm{~nm}$ light was analyzed. Every $5 \mathrm{~min}$, eight fluorescence video images were acquired, averaged, and saved to disk. To obtain plots of surface area versus time, the surface area of the leading edge was measured on each of the saved images. A potential problem with this approach is that when cells are excited with $380 \mathrm{~nm}$ light, the intensity of emission of Fura-2 decreases with increasing calcium concentration. Thus, if calcium concentration rose to a very high level, this method would lead to an underestimate of the surface area. Experiments in which the free calcium was estimated by ratio imaging (see below) indicate that this is unlikely to be a problem in the experiments reported here. Even at the highest concentration of calcium detected in response to myelin, the fluorescence when excited at $380 \mathrm{~nm}$ was much brighter than the fluorescence in response to 340 $\mathrm{nm}$, and the entire outline of the growth cone could easily be distinguished (see Fig. 2). A further check of the accuracy of this method was made by comparing surface areas measured on phase-contrast images after the myelin extract was washed off with surface areas measured on the fluorescent images after the myelin extract was in contact with the growth cones for an hour. The changes in surface area measured using these two methods were not significantly different $(p<0.01)$ (see Fig. 3).

\section{Fura-2 microscopy}

Cells were loaded with Fura-2 acetoxymethyl ester (AM) by incubating them in the external recording solution (see below) containing Fura-2AM $(3 \mu \mathrm{M})$ and Pluronic detergent ( $1 \% \mathrm{wt} / \mathrm{vol})$. Cells were incubated in the Fura-2 solution for $90 \mathrm{~min}$ at $37^{\circ} \mathrm{C}$, rinsed twice with normal media, and returned to the incubator for $60 \mathrm{~min}$ before being placed on the microscope stage for experimental observation.

Fura-2 ratio measurements were made using two different systems; a photometry system (Delta Scan, Photon Technology Inc.) attached to a Nikon DiaPhot microscope with a $40 \times$-fluor oil immersion objective, and a vidco-based system (IMAGE $1 / \Gamma L$, Universal Imaging Inc.) that used an SIT camera mounted on a Zeiss IM inverted microscope equipped with a computer-controlled shutter and filter wheel and a $40 \times-U V$ glycerine immersion objective. The photometry system allowed data to be collected more rapidly, at the loss of spatial resolution. Ratio measurements were made 20 times per second on the photometry system, but images could be acquired and saved only once every 3-4 sec on the video system. All experiments using the photometry system were per- 

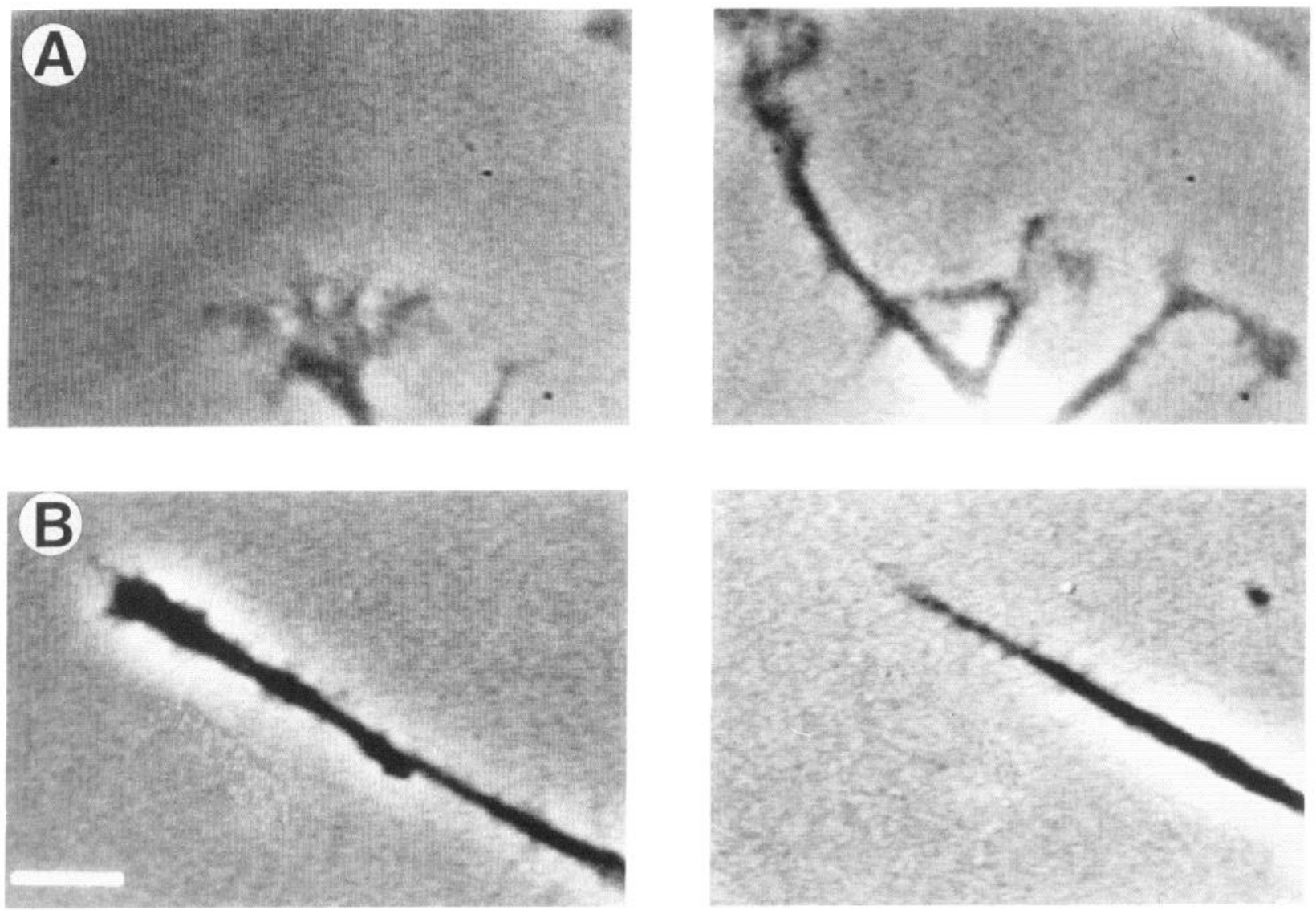

Figure 1. Phase-contrast images of growth cones of neonatal rat locus coeruleus neurons that had been in culture for 2-5 d. In each case, the image on the right was acquired $60 \mathrm{~min}$ after the image on the left. $A$, Cell continuously bathed in normal medium. $B$, Cell exposed to CNS myelin just after the first image. Scale bar, $10 \mu \mathrm{m}$.

formed at room temperature, and all experiments using the video system were performed at $37^{\circ} \mathrm{C}$.

For each growth cone studied, an initial series of measurements were made to verify that there was a steady baseline calcium concentration. The final $25 \mathrm{sec}$ of the baseline data were stored and then the acquisition program was paused. A myelin-containing puffer pipette was then brought close to the growth cone. Myelin was puffed onto the growth cone and the micropipette was removed from the dish. Data acquisition was then resumed. This procedure, which took $15-30 \mathrm{sec}$, was necessary because the pipette degraded the image when it was in the field. The ratios of fluorescence values were converted into free calcium concentrations using two methods. A calibration curve of ratio values versus calcium concentration was generated using Fura-2 free acid in solutions of known free calcium concentrations. Ratio values were also converted to calcium concentrations using the formula of Grynkiewicz et al. (1985), assuming $K_{d}=224 \mu \mathrm{M}$. The two methods yielded calcium concentrations that were within $10 \%$ of each other. All drugs tested were made as concentrated stocks and then diluted into both the medium bathing the cells and into the myelin-containing solution in the puffer pipette. A $t$ test for means from unequal sample sizes was used to compare average resting internal free calcium concentration $\left([\mathrm{Ca}]_{i}\right)$ levels in each group, average maximal $[\mathrm{Ca}]_{i}$ levels reached after contact with myelin in each group, and average change in $[\mathrm{Ca}]_{i}$ evoked by contact with myelin in each group.

In experiments in which we simultaneously recorded membrane potential and Fura-2 fluorescence, we measured only the emission in response to $380 \mathrm{~nm}$ excitation. The reason was that the movements of the filter wheel made it difficult to obtain stable recordings. The expectation was that the fluorescence in response to $380 \mathrm{~nm}$ excitation would fall when $[\mathrm{Ca}]_{i}$ increased. However, a decrease in fluorescence might also occur if the myelin extract decreased the transmission of light through the optical path. To control for changes in the optical path after myelin was added, a fluorescence intensity ratio was calculated. The fluorescence of an area containing no cells was divided by the fluorescence emitted from the cell under study. Although this ratio was not easily calibrated, it increased with increases in $[\mathrm{Ca}]_{i}$, and was sufficient to verify whether or not $[\mathrm{Ca}]_{i}$ changed.

\section{Electrophysiological measurements}

We made whole-cell voltage-clamp recordings (Hamill et al., 1981) to determine which classes of voltage-gated calcium channels are present in neonatal rat locus coeruleus neurons. All voltage-clamp recordings were performed at room temperature. Voltage-clamp recordings were made in the whole-cell configuration from the cell bodies of freshly dissociated locus coeruleus neurons and from locus coeruleus neurons that had been in cell culture for varying periods of time. Solutions that would block both $\mathrm{Na}$ and $\mathrm{K}$ currents were used. The recording bath solution (external) contained $\mathrm{CaCl}_{2}, 5 \mathrm{~mm}$; tetraethylammonium (TEA)$\mathrm{Cl}, 120 \mathrm{~mm} ; \mathrm{MgCl}_{2}, 2 \mathrm{~mm}$; HEPES, $10 \mathrm{~mm}$; and tetrodotoxin, $19 \mathrm{~nm}$. The $\mathrm{pH}$ was adjusted to 7.3 with $\mathrm{CsOH}$. The osmolality was adjusted to $300 \mathrm{mOsm}$ with sucrose. The recording pipette solution (internal) contained $\mathrm{CsCl}, 120 \mathrm{~mm}$; TEA-Cl, $20 \mathrm{~mm} ; \mathrm{MgCl}_{2}, 2 \mathrm{~mm}$; EGTA, 10 $\mathrm{mm}$; and HEPES, $10 \mathrm{~mm}$. The $\mathrm{pH}$ was adjusted to 7.3 with $\mathrm{CsOH}$. The osmolality was adjusted to $300 \mathrm{mOsm}$ with sucrose. Voltage-clamp paradigms and data acquisition were done with pCLAMP 5.5 (Axon Instruments). For each cell, maximal current evoked by each voltage step from each holding potential was normalized against the maximal current evoked by a step to $0 \mathrm{mV}$ from a holding potential of $-100 \mathrm{mV}$. Currentvoltage relationships were determined by plotting average normalized evoked current versus membrane potential. Average maximal normalized currents evoked from each holding potential were compared using a $t$ test.

We also made whole-cell current-clamp recordings and intracellular recordings to determine whether the CNS myelin extract caused a change in membrane potential that might open voltage-gated channels. All 

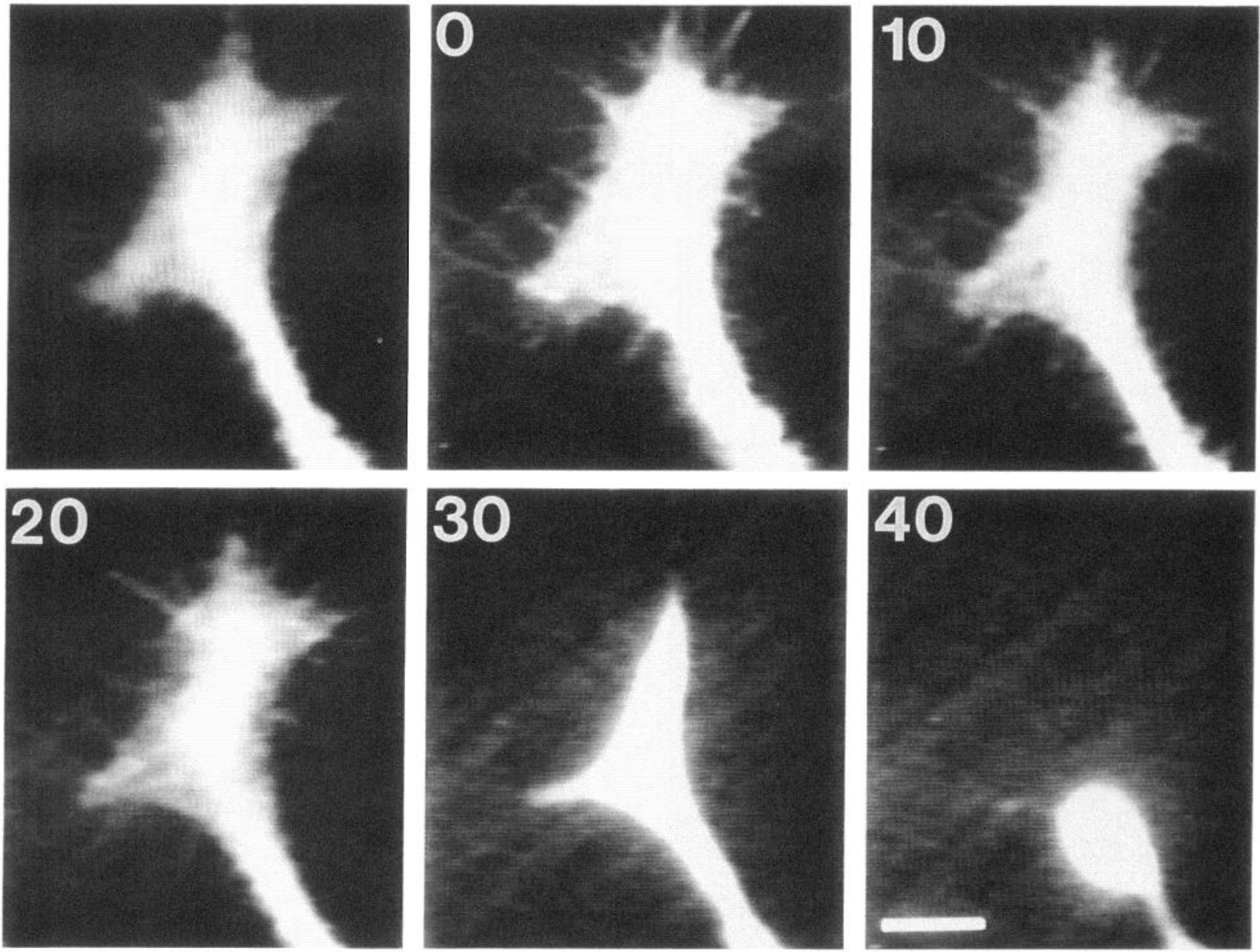

Figure 2. Time course of growth cone collapse following application of CNS myelin. This locus coeruleus neuron was loaded with Fura-2, and its morphology was monitored by imaging the fluorescence in response to $380 \mathrm{~nm}$ excitation. The same growth cone was imaged at various times. The first two images are immediately before and after myelin application. The remaining images were collected at the times after the CNS myelin application (in minutes) indicated in each panel. Scale bar, $10 \mu \mathrm{m}$.

current-clamp recordings and intracellular recordings were done at room temperature on cells that had been in culture for $1-2 \mathrm{~d}$. For the wholecell current-clamp recordings, the recording bath solution contained $\mathrm{NaCl}, 132 \mathrm{~mm} ; \mathrm{KCl}, 5 \mathrm{~mm} ; \mathrm{CaCl}_{2}, 5 \mathrm{~mm} ; \mathrm{NaH}_{2} \mathrm{PO}_{4}, 1.3 \mathrm{~mm} ; \mathrm{MgSO}_{4}$, $1.7 \mathrm{~mm}$; HEPES, $10 \mathrm{~mm}$; and glucose, $0.3 \mathrm{~mm}$. The $\mathrm{pH}$ was adjusted to 7.3 with $\mathrm{NaOH}$. The osmolality was adjusted to $300 \mathrm{mOsm}$ with sucrose. For the intracellular recordings the recording bath solution was the normal culture media plus HEPES $(10 \mathrm{~mm})$. For whole-cell recording, the recording pipette contained $\mathrm{KCl}, 135 \mathrm{~mm}$; EGTA $\mathrm{KOH}, 10$ $\mathrm{mm} ; \mathrm{MgCl}_{2}, 2 \mathrm{~mm} ; \mathrm{CaCl}_{2}, 1 \mathrm{~mm} ; \mathrm{NaCl}, 1 \mathrm{~mm}$; HEPES, $10 \mathrm{~mm}$; and glucose, 10 mм. The $\mathrm{pH}$ was adjusted to 7.3 with $\mathrm{KOH}$. The osmolality was adjusted to $300 \mathrm{mOsm}$ with sucrose. Cells were current clamped while at their resting potential. For intracellular recording, the recording pipette contained $\mathrm{KCl}, 135 \mathrm{~mm} ; \mathrm{MgCl}_{2}, 2 \mathrm{~mm} ; \mathrm{NaCl}, 1 \mathrm{~mm}$; HEPES, $10 \mathrm{~mm}$; and glucose, $10 \mathrm{~mm}$. The $\mathrm{pH}$ was adjusted to 7.3 with $\mathrm{KOH}$. The osmolality was adjusted to 300 mOsm with sucrose. Prior to application of myelin, cells were stimulated to produce action potentials to confirm that the cells were capable of responding to a depolarizing stimulus. Membrane potential was recorded for several minutes before application of myelin and for 6 min after application of myelin.

\section{Results}

Growth cones of rat locus coeruleus neurons collapsed on contact with CNS myelin

Video microscopic observations were made of neonatal rat locus coeruleus neurons maintained at $37^{\circ} \mathrm{C}$. Locus coeruleus neuron growth cones elongated at an average rate of $17.9( \pm 1.9 ;$ SEM) $\mu \mathrm{m} / \mathrm{hr}(n=7)$ in normal media while not in contact with any other cells (Fig. 1 $A$ ). Once a stable growth rate had been established, myelin extract was puffed onto the growth cone. After a $60 \mathrm{~min}$ period the myelin was washed off, and the size and position of each growth cone were recorded. By $60 \mathrm{~min}$ after application of CNS myelin extract, 12 of 16 growth cones were collapsed (Fig. 1B). The average elongation rate during the hour of contact was $-7.4( \pm 2.3) \mu \mathrm{m} / \mathrm{hr}$ (a negative average growth rate indicates retraction). The average change in surface area during the hour of contact was $-73.2 \%( \pm 5.6, n=16)$. Neither heat-inactivated CNS myelin $(n=5)$ nor trypsin-treated CNS myelin $(n=5)$ evoked growth cone collapse.

In contrast to the effects of CNS myelin, zero of five growth cones collapsed after $60 \mathrm{~min}$ of contact with an extract of myelin from the adult rat ischiatic nerve (PNS myelin extract) prepared in an identical manner to the CNS myelin extract. These growth cones elongated at an average rate of $10.2( \pm 0.9) \mu \mathrm{m} / \mathrm{hr}$ before contact with myelin, and at $11.5( \pm 0.5) \mu \mathrm{m} / \mathrm{hr}$ while in contact with the myelin extract. These results indicate that PNS and CNS myelin extracts have very different effects on the rate of growth cone elongation and growth cone morphology of locus coeruleus neurons, as has been reported previously for other neonatal rat neurons (Caroni and Schwab, 1988b).

To determine the time course of growth cone collapse, we made observations of fluorescently labeled growth cones once every $5 \mathrm{~min}$ for $60 \mathrm{~min}$. This approach was taken because the 


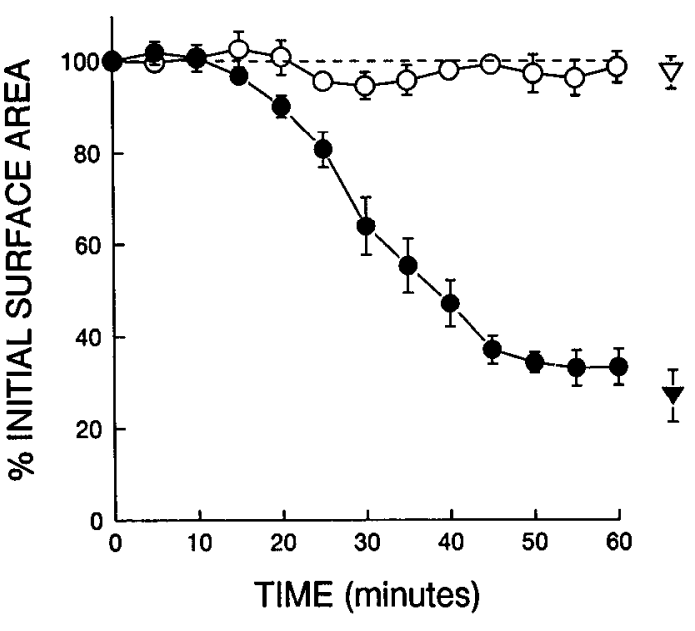

Figure 3. Time course of surface area change during growth cone collapse following application of CNS myelin. The surface area of the growth cone was determined by measuring fluorescent-video images of Fura-2 loaded growth cones excited at $380 \mathrm{~nm}$. Surface area at each time point was normalized against surface are at time 0 . Open circles represent surface area of untreated growth cones $(n=5)$. Solid circles represent surface area of growth cones when CNS myelin extract was applied at time $0(n=5)$. The open triangle represents the surface area of untreated growth cones viewed with phase-contrast video microscopy $(n=16)$. The solid triangle represents surface area of growth cones viewed with phase-contrast video microscopy after the CNS myelin extract was washed of $(n=16)$. and demonstrate that fluorescence imaging does not underestimate the surface area of the growth cones. Error bars represent SEM.

myelin extract was highly refractive, and did not allow for highresolution observation of growth cones with phase-contrast or Nomarski optics during the time that the myelin was in contact with the growth cone. During the first $15 \mathrm{~min}$ after contact with CNS myelin there was no consistent change in the morphology of these growth cones (Fig. 2). Between 15 and 30 min there was a variable $(25-60 \%)$ decrease in the surface area of the growth cones (Fig. 3). By $45 \mathrm{~min}$, these growth cones had 25$40 \%$ of their original surface area. Thus, the collapse of these growth cones occurs with a rather protracted time course.

\section{CNS myelin evoked an increase in intracellular free calcium}

In this first series of experiments, the intracellular free calcium concentration $\left([\mathrm{Ca}]_{i}\right.$ ) within neonatal rat locus coeruleus neurons loaded with Fura-2 was measured using the photometry system and neurons were maintained at room temperature. Application of CNS myelin extract to the growth cones of these neurons consistently caused a large, transient, increase in $[\mathrm{Ca}]_{i}$. Within the first 6 min after application of CNS myelin, an elevation in intracellular free calcium was observed in 9 of 12 growth cones studied. On average, the resting intracellular free calcium more than doubled from $94 \mathrm{~nm}$ to $237 \mathrm{~nm}$ (Table 1). The increase in $[\mathrm{Ca}]_{i}$ occurred at a variable latency after application of the myelin extract to the growth cones. In some cases the latency was as long as several minutes (Fig. $4 A$ ) while in other cases the calcium had begun to rise by the time that data acquisition began (Fig. $4 B$ ). The average latency from the initiation of myelin application to the peak of the calcium transient was 70.5 $\pm 8.7 \mathrm{sec}$. The time course of the calcium transient also varied from cell to cell, but in all cases $(n-9)$ the elevation in calcium lasted less than $2 \mathrm{~min}$. It seemed possible that the slow and variable time course of the change in $[\mathrm{Ca}]_{i}$ might be a conse-

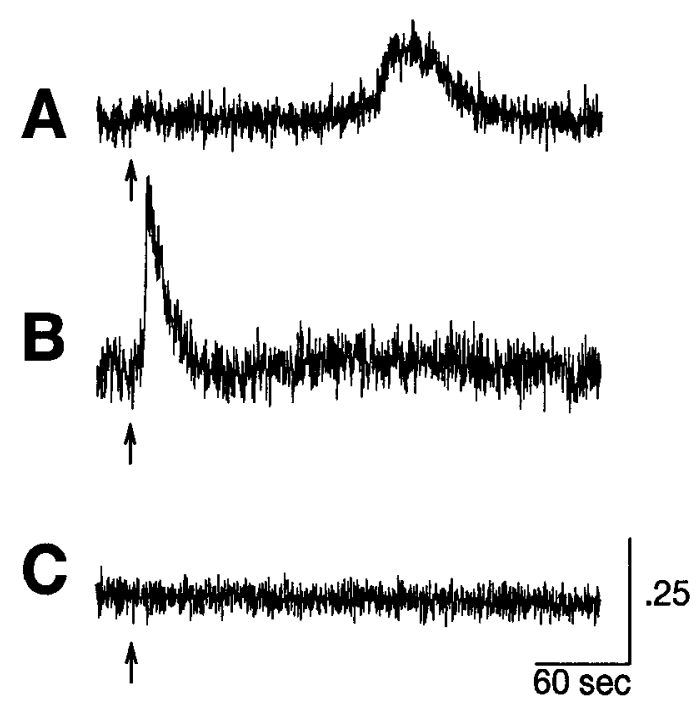

Figure 4. Determination of intracellular free calcium in growth cones using the photometry system. The arrows indicate the time that data collection resumed following application of the myelin (about 20-30 sec after myelin was applied). The vertical scale indicates the ratio of $A_{350}: A_{380} . A$ and $B$, Two examples of the effect of application of CNS myelin. Note the variable time course. $C$, PNS myelin did not elevate $[\mathrm{Ca}]_{i \cdot}$

quence of studying cells at room temperature. However, when five cells were studied at $37^{\circ} \mathrm{C},[\mathrm{Ca}]_{i}$ increased to about the same peak level (mean, $255 \pm 21$ ) and the increase still occurred at a variable time during the $6 \mathrm{~min}$ after the myelin application.

Treatments that failcd to cvokc growth cone collapse also failed to elicit a rise in intracellular free calcium. Thus, PNS myelin (Fig. 4C), heat-inactivated myelin, and trypsin-treated myelin all had no effect on the level of intracellular free calcium (Table 1). Since PNS and CNS myelin have many lipid and protein components in common (see Norton and Cammer, 1984), this argues against a nonspecific effect of the CNS myelin exiract causing the $[\mathrm{Ca}]_{i}$ increase.

An increase in intracellular free calcium might be due to influx of calcium through the plasma membrane, release of calcium from internal stores, or both (Miller, 1988). The myelin-evoked increase in $[\mathrm{Ca}]_{i}$ was blocked when calcium was removed from the extracellular solution (by chelation with 5 mM EGTA) and when a nonspecific blocker of several types of transmembrane calcium channels ( $5 \mathrm{mM} \mathrm{CoCl}_{2}$ ) was present in the extracellular solution (Table 2). These data suggested that the increase in $[\mathrm{Ca}]_{i}$ was the result of an influx of calcium through the plasma membrane.

Table 1. The effects of application of different myelin extracts to growth cones of neonatal rat locus coeruleus neurons

\begin{tabular}{llll} 
Treatment $(n)$ & Resting $[\mathrm{Ca}]_{i}$ & ${\text { Maximum }[\mathrm{Ca}]_{i}}$ & Change \\
\hline $\begin{array}{c}\text { CNS myelin (12) } \\
\text { Heat-inactivated }\end{array}$ & $94 \pm 3$ & $237 \pm 18$ & 143 \\
$\quad$ CNS myelin (5) & $82 \pm 3$ & $82 \pm 3$ & 0 \\
Trypsin-treated & & & \\
$\quad$ CNS myelin (5) & $90 \pm 4$ & $90 \pm 4$ & 0 \\
PNS myelin (5) & $74 \pm 3$ & $74 \pm 3$ & 0
\end{tabular}

All calcium concentrations are shown as nM ( \pm SEM). 
Figure 5. $A-C$, Whole-cell calcium currents recorded from a neonatal rat locus coeruleus neuron that had been growing in culture for $1 \mathrm{~d}$. The external and internal recording solutions are described in Materials and Methods. The upper trace in each panel is the wholecell current evoked in response to the stimulus indicated in the lower trace of each panel. Capacitative transients in all traces have been clipped. In $A$ the step to $-50 \mathrm{mV}$ elicited no detectable calcium current. $D-F$, Current-voltage plots for neonatal rat locus coeruleus neurons in vitro. These are plots of the normalized peak currents evoked by voltage steps from $-100 \mathrm{mV}(D),-70$ $\mathrm{mV}(E)$, or $-30 \mathrm{mV}(F)$ to the potentials indicated on the $x$-axis. Each plot represents the average of the same five cells. The peak currents were normalized as described in Materials and Methods. Error bars represent SEM. In the cases where it appears as if there are no error bars, the bars are smaller than the data symbol.
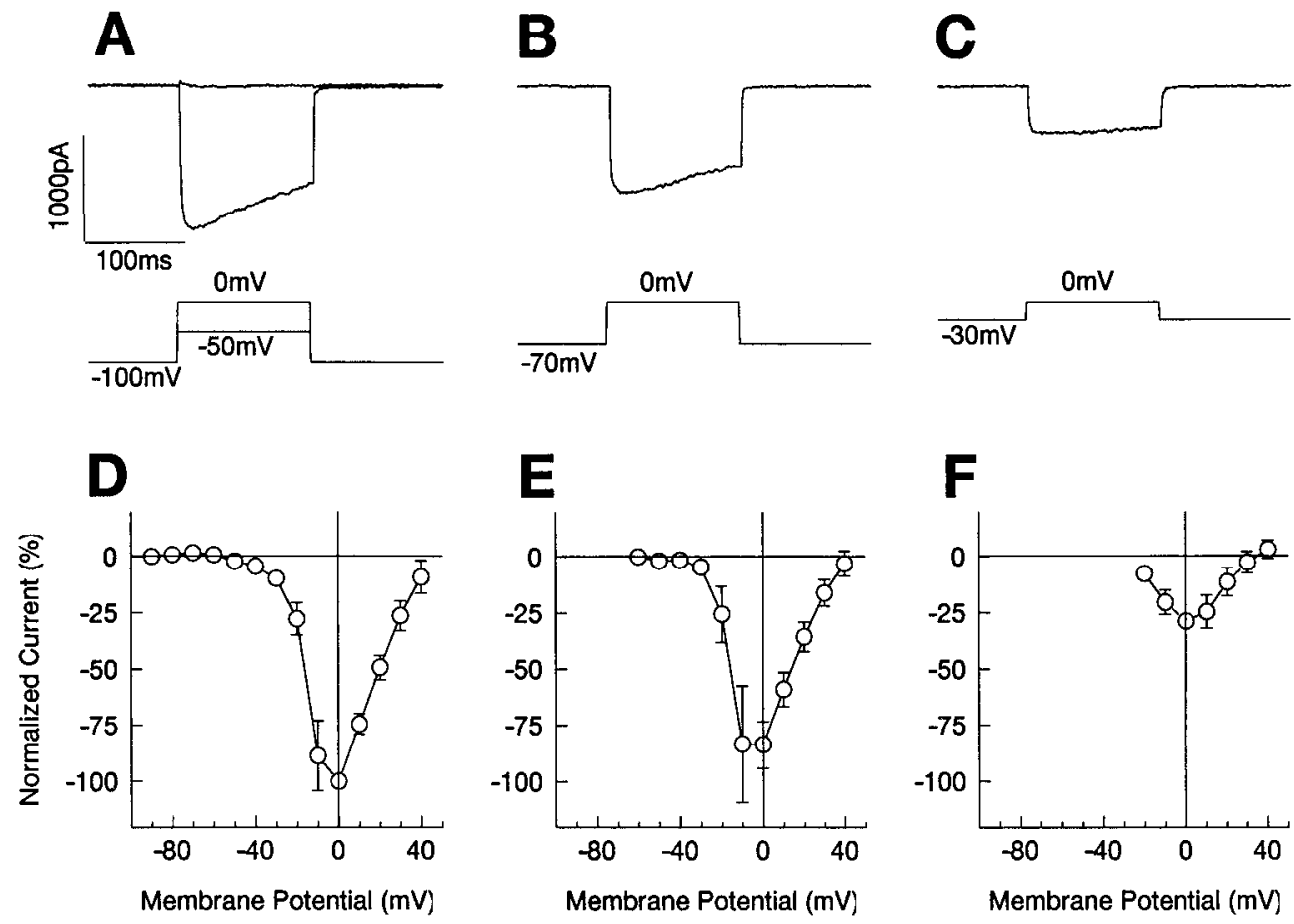

\section{Calcium channel types in neonatal rat locus coeruleus neurons}

In locus coeruleus neurons, one route of calcium entry might be through voltage-gated channels with high permeability to calcium. To determine the types of calcium channels present in neonatal rat locus coeruleus neurons, we made whole-cell voltage clamp recordings on these neurons in vitro, under conditions in which currents other than calcium currents were suppressed. We used voltage-step paradigms that have been used in other systems to separate low-voltage-activated channels (T-type) from high-voltage-activated channels ( $\mathrm{N}$ - and L-type) (see Hess, 1990). Typical recordings made from the cell body of one neuron are shown (Fig. $5 A-C$ ) as is the average current-voltage data from five cells (Fig. $5 D, E$ ).

There was little or no inward current when the membrane potential was stepped to $-50 \mathrm{mV}$ from a holding potential of $-100 \mathrm{mV}$ (Fig. 5A,D). These data suggest that there is little, if any, low-voltage-activated (T-type) current in these neurons. However, when the membrane potential was stepped to $0 \mathrm{mV}$ from a holding potential of $-100 \mathrm{mV}$ there was a large inward current that decayed with time. There was only a modest decrease in the peak amplitude of the inward current when cells

Table 2. The effects of application of myelin extract to growth cones of nconatal rat locus cocrulcus neurons in media containing different drugs

\begin{tabular}{lrrr} 
Treatment $(n)$ & $\begin{array}{c}\text { Resting } \\
{[\mathrm{Ca}]_{i}}\end{array}$ & $\begin{array}{l}\text { Maximum } \\
{[\mathrm{Ca}]_{i}}\end{array}$ & Change \\
\hline $5 \mathrm{mM} \mathrm{EGTA}(6) \mathrm{mM} \mathrm{CoCl}_{2}(6)$ & $79 \pm 4$ & $79 \pm 4$ & 0 \\
$75 \mu \mathrm{M}_{\text {diphenylhydantoin }}(6)$ & $128 \pm 7$ & $129 \pm 6$ & 1 \\
$50 \mu \mathrm{M}$ nifedipine (7) & $106 \pm 8$ & $279 \pm 23$ & 163 \\
$5.0 \mu \mathrm{M} \omega$-conotoxin (9) & $78 \pm 3$ & $89 \pm 3$ & 11 \\
\hline
\end{tabular}

All calcium concentrations are shown as nM $( \pm$ SEM $)$. were held at $-70 \mathrm{mV}$ rather than $-100 \mathrm{mV}$ and then stepped to $0 \mathrm{mV}$ (Fig. $5 B, D$ ). However, when cells were held at -30 $\mathrm{mV}$ (Fig. $5 C, F$ ), the currents at $0 \mathrm{mV}$ were much smallcr than those evoked from more negative holding potentials. Moreover, the current evoked from a holding potential of $-30 \mathrm{mV}$ displayed little detectable decline in amplitude during the test pulse. These results are consistent with the properties of L-type channels in other neurons (see Hess, 1990). By analogy to other systems, the current that was inactivated by a holding potential of $-30 \mathrm{mV}$ is referred to as $\mathrm{N}$-type. Therefore, our data suggest that neonatal rat locus coeruleus neurons have $\mathrm{N}$ - and L-type calcium channels but not $\mathrm{T}$-type channels during the first week in vitro. We also made whole-cell recordings from isolated growth cones of these neurons $(n=3)$ with similar results.

\section{$\omega$-Conotoxin blocked the myelin-evoked increase in $[\mathrm{Ca}]_{\mathrm{i}}$}

To test whether the $[\mathrm{Ca}]_{i}$ increase evoked by application of CNS myelin extract onto growth cones was related to calcium flux through $\mathrm{N}$ - and/or L-type voltagc-gatcd calcium channels, we blocked these channel types using specific drugs. L-type channels can be selectively blocked with dihydropyridines such as nifedipine (see Tsien et al., 1988); N-type channels can be selectively blocked by $\omega$-conotoxin GVIA (conotoxin) (Olivera et al., 1987); and T-type channels in some cells can be blocked by diphenylhydantoin (Yaari et al., 1987). Cells treated with $75 \mu \mathrm{M}$ diphenylhydantoin, or $50 \mu \mathrm{M}$ nifedipine in the media each had a resting $[\mathrm{Ca}]_{i}$ level that was slightly, but significantly, higher $(p$ $<0.05$ ) than that of the control group (Table 2). Resting [Ca] was not significantly elevated by conotoxin (Table 2). Diphenylhydantoin had no effect on the myelin-evoked [Ca $]_{i}$ increase (Table 2); this was expected since the electrophysiology data suggested that these cells do not have T-type channels. Nifedipine significantly reduced the magnitude of the $[\mathrm{Ca}]_{i}$ increase evoked by contact with myelin (Table 2). However, even with $50 \mu \mathrm{M}$ nifedipinc, a concentration that would be expected to be saturating (McCleskey et al., 1986), myelin extract was able to 

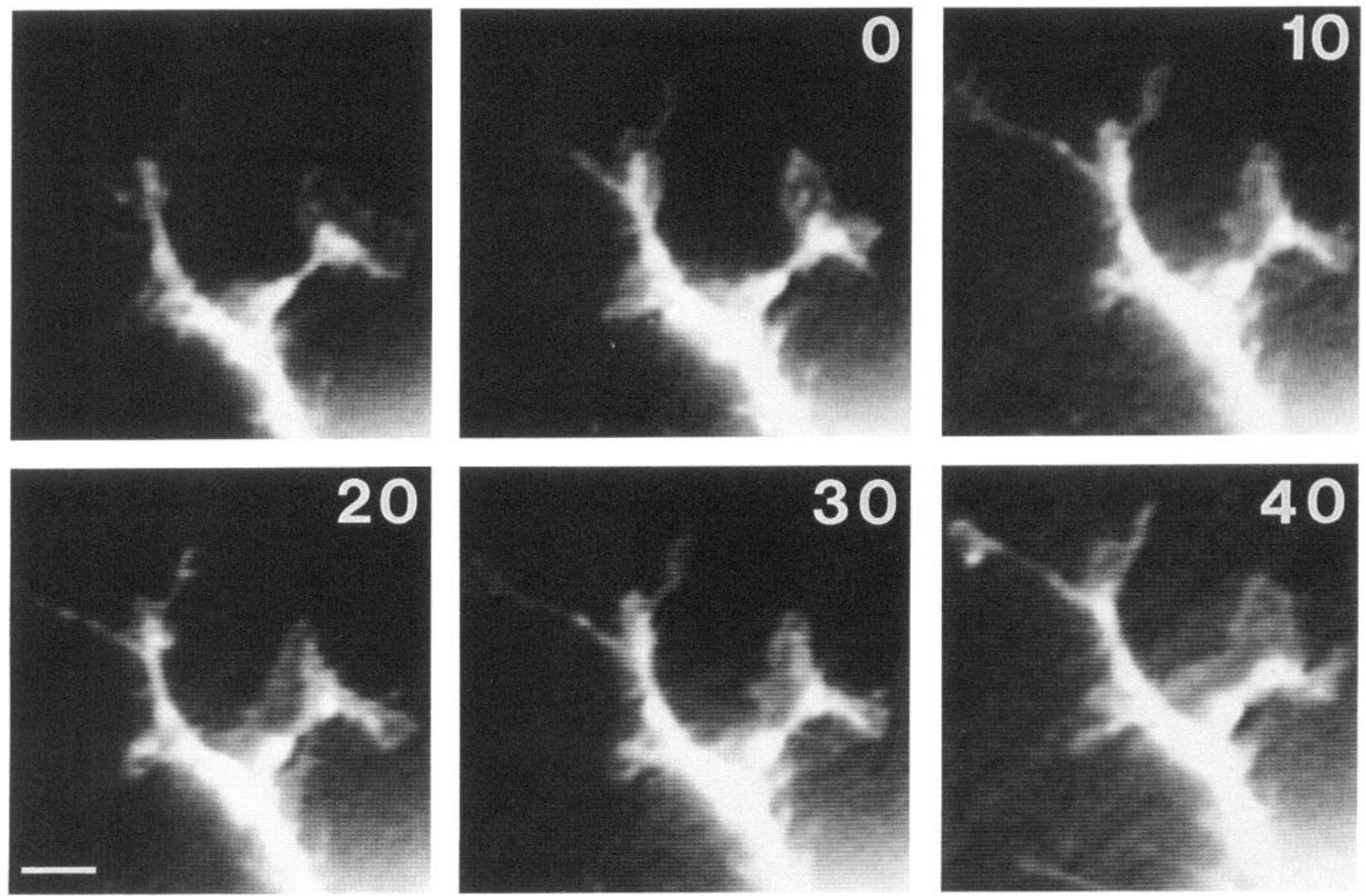

Figure 6. $\omega$-Conotoxin prevented myelin-evoked growth cone collapse. Locus coeruleus neurons were loaded with Fura-2, and their morphology was monitored by imaging the fluorescence at $380 \mathrm{~nm}$. The same growth cone was imaged at various times. The first two images were taken immediately before and after myelin application. The remaining images were collected at the times after the CNS myelin application (in minutes) indicated in each panel. There was no indication of even transient collapse, and the growth cone continued to elongate. Scale bar, $10 \mu \mathrm{m}$.

increase intracellular free calcium significantly (Table 2). These results suggest that calcium flux through L-type voltage-gated calcium channels cannot fully account for the increase in $[\mathrm{Ca}]_{i}$. In contrast, conotoxin was able to suppress the myelin-evoked increase in $[\mathrm{Ca}]_{i}$ nearly completely (Table 2). At $5 \mu \mathrm{M}$, conotoxin has been reported to block calcium current through $\mathrm{N}$-type channels totally without effect on current through other calcium channels (Plummer et al., 1989; also see below).

\section{$\omega$-Conotoxin prevented myelin-evoked growth cone collapse}

Knowing how to block the increase in $[\mathrm{Ca}]_{i}$ evoked by contact with CNS myelin put us in a position to test whether this increase was necessary for evoking growth cone collapse. We made video microscopic observations of locus coeruleus neurons under conditions that partially or completely blocked the increase in $[\mathrm{Ca}]_{i}$. In media that contained $50 \mu \mathrm{M}$ nifedipine, 8 of 15 growth cones collapsed within $60 \mathrm{~min}$ after contact with CNS myelin. This is not very different from the control condition, where 12 of 16 collapsed after contact with CNS myelin. In contrast, conotoxin completely suppressed the effect of CNS myelin on growth cone morphology and elongation. When grown in media that contained $5 \mu \mathrm{M}$ conotoxin, the growth cones elongated at an average rate of $8.2( \pm 1.52) \mu \mathrm{m} / \mathrm{hr}(n=15)$ while not in contact with any other cells. When CNS myelin was then puffed onto these growth cones, they continued to elongate at an average rate of $9.45( \pm 0.86) \mu \mathrm{m} / \mathrm{hr}$, and when the growth cones were observed at $60 \mathrm{~min}$ after the myelin was added, 0 of 15 growth cones were collapsed.

Because physiological recordings showed that these neurons have both $\mathrm{N}$ - and L-type channels, and that these channels open over approximately the same voltage range, it was somewhat surprising that a specific blocker of $\mathrm{N}$-type channels alone was sufficient to block the myelin-evoked increase in $[\mathrm{Ca}]_{i}$ and growth cone collapse. We therefore tested the possibility that, at the concentrations used, conotoxin might block L-type currents in these neurons as well as $\mathrm{N}$-type currents. However, whole-cell recordings demonstrated that $5 \mu \mathrm{M}$ conotoxin did not block L-type currents (currents evoked from a holding potential of $-30 \mathrm{mV})$ in these neurons $(n=5)$.

Although no growth cones were observed to be collapsed after 60 min of contact with CNS myelin when conotoxin was present, this need not mean that conotoxin prevented collapse. Because of the optical effects of the myelin extracts on phase-contrast images, the behavior of these growth cones was not usually followed during the time that myelin was in contact with the growth cone. Therefore, rather than preventing collapse, it was possible that conotoxin was promoting a much more rapid recovery from collapse. If that were the case, an intact growth cone might have reformed by the time that observations were made at $60 \mathrm{~min}$. To assess more accurately the structure of growth cones while they were in contact with myelin, we observed several growth cones with fluorescence microscopy at 1 


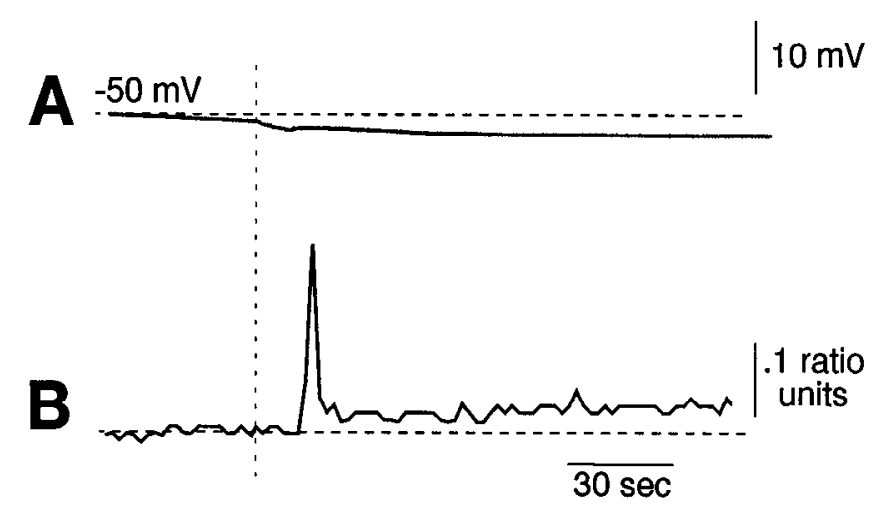

Figure 7. Simultaneous membrane potential and Fura-2 signals recorded from a locus coeruleus neuron that had been growing in culture for $1 \mathrm{~d}$. CNS myelin extract was applied from a puffer pipette at the time indicated by the vertical broken line. $A$, Membrane potential recorded using a standard fine-tipped, intracellular pipette. $B$, The ratio of the background signal to the Fura-2 fluorescence was calculated as described in Materials and Methods. An increase in the ratio corresponds to an increase in $[\mathrm{Ca}]_{i}$.

min intervals during $15 \mathrm{~min}$ to $1 \mathrm{hr}$ of contact with CNS myelin. In none of those six growth cones was there any indication of even a transient collapse (Fig. 6).

\section{Calcium influx can evoke growth cone collapse}

The preceding experiments indicated that exposure to $5 \mu \mathrm{M}$ conotoxin was sufficient to prevent collapse of the growth cone. The only known action of conotoxin is to block flux through $\mathrm{N}$-type channels. A working hypothesis is that influx through the N-type channels is the direct cause of the increase in $[\mathrm{Ca}]_{i}$, and that this increase in $[\mathrm{Ca}]_{i}$ is the cause of the growth cone collapse. To test this hypothesis we determined whether an increase in $[\mathrm{Ca}]_{i}$ similar in magnitude to that elicited by CNS myelin was sufficient to elicit growth cone collapse. Cells were loaded with Fura-2 so that $[\mathrm{Ca}]_{i}$ could be estimated, and the morphology of growth cones maintained at $37^{\circ} \mathrm{C}$ was assessed using the video-based system. Puffer application of the nonfluorescent calcium ionophore 4-bromo A23187 (10 $\mu \mathrm{M})$ onto growth cones for 5-10 sec evoked a transient increase in [Ca] that was comparable in duration and magnitude (peak $[\mathrm{Ca}]_{i}$, $253 \pm 12 \mathrm{nM} ; n=5$ ) to that evoked by CNS myelin. None of the five growth cones tested in this way collapsed during the hour that they were observed. However, when longer applications of A23187 were given $(15-20 \mathrm{sec})$, so that the average $[\mathrm{Ca}]_{i}$ reached $0.8-1 \mu \mathrm{M}$, five of five growth cones tested collapsed.

\section{CNS myelin does not cause membrane depolarization}

The results presented above suggest that CNS myelin exerts its effects on the growth cones of locus coeruleus neurons through voltage-gated calcium channels. One possible mechanism that could account for these results is if myelin elicits a depolarization that opens the channels. To test this hypothesis, we monitored membrane potential under whole-cell current-clamp conditions during application of CNS myelin extract. In cells held at their resting potential (range, -30 to $-50 \mathrm{mV}$ ), typically there was a small hyperpolarization in response to myelin (mean, -8.4 \pm 1.1 ), and in none of the eight cells studied did myelin give a depolarization of more than $5 \mathrm{mV}$. Because whole-cell recording can sometimes disrupt intracellular signaling, an additional set of experiments were performed in which membrane potential was measured with conventional fine-tipped micropipettes. Again, there was a slight hyperpolarization in response to myelin application (mean, $-6.3 \pm 0.8 ; n=12$ ). In four of these experiments we confirmed that the myelin caused an increase in $[\mathrm{Ca}]_{i}$ by simultaneously measuring membrane potential and Fura-2 fluorescence (Fig. 7). The implications of the absence of a depolarization in response to application of the myelin extract are considered in the Discussion.

\section{Discussion}

CNS myelin has been shown to evoke collapse of the growth cones of dorsal root ganglion (DRG) neurons in vitro (Caroni and Schwab, 1988a), and when CNS myelin is pretreated with antibodies against two CNS myelin-specific proteins, collapse of DRG growth cones is no longer evoked (Caroni and Schwab, 1988b). This phenomenon is thought to be relevant to recovery from spinal cord injury because these same antibodies significantly enhance spinal cord regeneration after injury in vivo (Schnell and Schwab, 1990). Some (Bandtlow et al., 1993), but not all (Ivins et al., 1991; Garyantes and Regehr, 1992), cases of growth cone collapse are associated with a change in intracellular free calcium. For this reason, we monitored $[\mathrm{Ca}]_{i}$ in neonatal rat locus coeruleus neurons when they were contacted by CNS or PNS myelin. We found that CNS, but not PNS, myelin could evoke a significant increase in $[\mathrm{Ca}]_{i}$ in locus coeruleus neurons. Because extracellular EGTA and extracellular cobalt can both prevent the increase in $[\mathrm{Ca}]_{i}$, the simplest interpretation is that it is due to a transmembrane flux. However, the specific CNS myelin proteins known to induce collapse of the growth cones of DRG neurons have recently been shown to cause a release of calcium from internal stores (Bandtlow et al., 1993). The possibility that, in our experiments, extracellular EGTA or extracellular cobalt might have depleted the internal store of calcium or interfered with release of calcium from an internal store cannot be totally excluded.

Another way that our results differ from those of Bandtlow et al. (1993) is that they observed that application of the protein purified from CNS myelin to the growth cones of DRG neurons caused the $[\mathrm{Ca}]_{i}$ to rise beyond $1 \mu \mathrm{M}$, which is much greater than the increase we observed in locus coeruleus neurons in response to myelin extract (peak $[\mathrm{Ca}]_{i}$ of about $250 \mathrm{~nm}$ ). One possible explanation for the smaller $[\mathrm{Ca}]_{i}$ increase seen in locus coeruleus neurons might be the difference in external calcium concentration used in the two sets of experiments. The medium we normally used for locus coeruleus neurons contained $0.4 \mathrm{~mm}$ calcium, while the studies using DRG cells used $1.5-2.0 \mathrm{~mm}$ calcium, which is closer to the normal physiological level. However, when a series of locus coeruleus neurons bathed with an extracellular solution containing $1.3 \mathrm{~mm}$ calcium were studied, the increase in $[\mathrm{Ca}]_{i}$ evoked by CNS myelin was slightly higher (186 nM compared to $143 \mathrm{nM}$ ), but not significantly different from that evoked in media with $0.4 \mathrm{~mm} \mathrm{Ca}(n=7)$. Another possible explanation for the lower peak $[\mathrm{Ca}]_{i}$ in locus coeruleus neurons is that the concentration of active material in the CNS myclin extract we used is low. This possibility is supported by the observation of Bandtlow et al. (1993) that the $[\mathrm{Ca}]_{i}$ increase in DRG neurons is directly related to the concentration of protein incorporated into the liposomes. A low concentration of the active molecule in our myelin extract or the presence of other molecules normally found on the surface of oligodendrocytes might also explain why the time of onset of the increase in $[\mathrm{Ca}]_{i}$ was so variable. An additional possibility is that central and 
peripheral neurons respond differently to CNS myelin. Consistent with this idea is the observation of Bandtlow et al. (1993) that $\omega$-conotoxin had no effect on growth cone collapse in DRG cells.

\section{Is calcium flux through voltage-gated channels the signal for growth cone collapse?}

The ability of $\omega$-conotoxin to block both the increasc in $[\mathrm{Ca}]_{i}$ and growth cone collapse is certainly suggestive of a role for calcium influx in growth cone collapse. However, several observations suggest caution. First, there is not a tight temporal correlation between the two events. Following contact with CNS myelin, $[\mathrm{Ca}]_{i}$ rose to a peak within a few minutes, and within 2 min after $[\mathrm{Ca}]_{i}$ began to rise, $[\mathrm{Ca}]_{i}$ had returned to premyelin application levels. However, collapse of the growth cone occurred 20-60 min later. These results suggest that if the rise in $[\mathrm{Ca}]_{i}$ plays a role, it is likely to be involved in the initiation of collapse, rather than in its actual expression. Alternatively, a rise in $[\mathrm{Ca}]_{i}$ is necessary but not sufficient to bring about collapse of the growth cone. One explanation for the variable time course of the $[\mathrm{Ca}]_{i}$ increase in these growth cones is that some second messenger pathway is involved. This idea is supported by the recent observation that a pertussis toxin-sensitive $G$-protein is involved in the pathway that induces collapse of growth concs from some types of neurons in response to both CNS myelin extract and one specific CNS myelin protein known to induce growth cone collapse (Igarashi et al., 1993).

A second major concern is that when A23187 was applied from a puffer pipette onto growth cones of neonatal rat neurons at a concentration that resulted in a similar increase in $[\mathrm{Ca}]_{i}$ to that evoked by myelin, there was no collapse of the growth cones during the hour that these growth cones were observed. One interpretation of this result is that it provides evidence to reject the hypothesis that calcium has a required role in the myelinevoked growth cone collapse. However, elevating calcium to slightly higher concentrations did evoke collapse. An alternative interpretation, which is compatible with a role for $[\mathrm{Ca}]_{i}$, is that the average $[\mathrm{Ca}]_{i}$ reported by the Fura- 2 is lower than the concentration of calcium at the key regulatory site within the cell. There is considerable evidence that the local calcium concentration in the vicinity of calcium channels can be much higher than the bulk intracellular calcium concentration reported by calcium indicators (see Augustine and Neher, 1992).

A third apparent concern is that both $\mathrm{L}$ - and $\mathrm{N}$-type channels are present, and activate over similar voltage changes, yet a compound that blocks L-type channels had only a modest effect, and a compound that blocks $\mathrm{N}$-type channels, a dramatic effect. The failure of nifedipine to block growth cone collapse might be a simple consequence of the relative magnitude of currents in locus coeruleus neurons. The whole-cell recordings indicated that approximately $75 \%$ of the calcium current at $0 \mathrm{mV}$ is $\mathrm{N}$-type and $25 \%$ L-type (Fig. 5). Thus, it is not surprising that a blocker of N-type channels would have a more dramatic effect on calcium levels. Consistent with this idea is the observation that nifedipine appeared to decrease slightly the fraction of growth cones collapsing in response to $\mathrm{CNS}$ myelin.

The final concern is the most perplexing. Several lines of evidence suggest that myelin elicits the entry of calcium through voltage-dependent transmembrane channels. However, Figure 5 showed that under control conditions the N-type calcium channels do not open significantly at the resting potential of -30 to $-50 \mathrm{mV}$ and Figure 7 showed that no depolarization results from application of myelin. How might these results be reconciled? If $\mathrm{N}$-type channels open in response to myelin, then the lack of myelin-induced membrane depolarization suggests that CNS myelin causes these voltage-gated calcium channels to open through a mechanism other than membrane depolarization. For instance, the putative second messenger pathway might shift the activation range of the $\mathrm{N}$-type channels to more negative potentials, so they have a higher probability of being open at the resting potential. As yet there is no information on this point, because the whole-cell recording conditions necessary to observe calcium currents would be expected to abolish the second messenger pathway that is proposed to cause the change. No matter what causes calcium channels to open, calcium influx through open channels should cause a depolarization, and yet no depolarization was observed in response to myelin. One possible explanation is that some other current masks the depolarizing effect of calcium entry. For instance, if calcium-activated potassium channels were located near the calcium channels, then the observable effect of calcium entry might be to elicit a hyperpolarization. This dominance of the secondary activation of a calcium-dependent potassium current over the primary transmembrane flux of calcium is thought to occur when $\mathrm{ACh}$ is applied to cochlear outer hair cells (Housley and Ashmore, 1991). Alternatively, the putative sccond messenger pathway might simultaneously activate both calcium and potassium channels, leading to little change in membrane potential.

In view of these concerns, alternative hypotheses to explain our results must be considered. Although the only known action of $\omega$-conotoxin it to inhibit $\mathrm{N}$-type calcium channels, it is always possible that the toxin also effects some unknown molecule that plays a key role in the collapse of growth cones. Another possibility is that the opening of N-type channels is required for the collapse, but only in an indirect way. For instance, if the calcium that triggers collapse comes from an intracellular store, entry of calcium across the plasma membrane might still be necessary to keep the store provisioned with calcium. By this hypothesis, blocking the transmembrane calcium channels with $\omega$-conotoxin would be inhibitory because it depletes the internal pool that was the dircet source of calcium. As notcd above, our experiments with extracellular EGTA and cobalt argue against release from an internal store, but do not completely rule out this hypothesis, since these compounds too might deplete an internal store. As noted above, Bandtlow et al. (1993) suggest that the myelin-induced growth cone collapse in DRG neurons involves a release of calcium from internal stores.

In conclusion, the mechanism by which myelin extract elicits the collapse of the growth cones of locus coeruleus neurons remains unclear. However, the observation that treatment with $\omega$-conotoxin blocks both the $[\mathrm{Ca}]_{i}$ increase and the growth cone collapse of neurons in vitro cannot be ignored, since it suggests a possible new approach to encouraging CNS axonal regeneration in vivo.

\section{References}

Anglister L, Farber IC, Sharar A, Grinvald A (1982) Location of voltage sensitive calcium channels along developing neurites: their possible role in regulation of neurite elongation. Dev Biol 94:351365.

Augustine GJ, Neher E (1992) Neuronal calcium signaling takes the local route. Curr Opin Neurobiol 2:302-307.

Bandtlow CE, Schmidt MF, Hassinger TD, Schwab ME, Kater SB (1993) 
Role of intracellular calcium in NI-35-evoked collapse of neuronal growth cones. Science 259:80-83.

Brundin P, Strecker RE (1991) Preparation and intracerebral grafting of dissociated fetal brain tissue in rats. In: Methods in neurosciences, Vol 7 (Conn PM, ed), pp 305-326. San Diego: Academic.

Caroni P, Schwab ME (1988a) Two membrane protein fractions from rat central myelin with inhibitory properties for neurite growth and fibroblast spreading. J Cell Biol 106:1281-1288.

Caroni P, Schwab ME (1988b) Antibody against myelin-associated inhibitor of neurite growth neutralizes nonpermissive substrate properties of CNS white matter. Neuron 1:85-96.

Forssberg H, Grillner S (1973) The locomotion of the acute spinal cat injected with clonidine i.v. Brain Res 50:184-186.

Garyantes TK, Regehr WG (1992) Electrical activity increases growth cone calcium but fails to inhibit neurite outgrowth from rat sympathetic neurons. J Neurosci 12:96-103.

Grynkiewicz G, Poenie M, Tsien RY (1985) A new generation of calcium indicators with greatly improved fluorescent properties. J Biol Chem 260:2440-2450.

Hamill OP, Marty A, Neher E, Sakmann B, Sigworth FJ (1981) Improved patch-clamp techniques for high-resolution current recording from cells and cell-free membrane patches. Pfluegers Arch 391:85100.

Hess P (1990) Calcium channels in vertebrate cells. Annu Rev Neurosci 13:337-356.

Honig MG, Hume RI (1986) Fluorescent carbocyanine dyes allow living neurons of identified origin to be studied in long-term cultures. J Cell Biol 103:171-187.

Housley GD, Ashmore JF (1991) Direct measurement of the action of acetylcholine on isolated hair cells of the guinea pig cochlea. Proc R Soc Lond [Biol] 244:161-167.

Igarashi M, Strittmatter SM, Vartanian T, Fishman MC (1993) Mediation by $G$ proteins of signals that cause collapse of growth cones. Science 259:77-80.

Ivins JK, Raper JA, Pittman RN (1991) Intracellular calcium levels do not change during contact-mediated collapse of chick DRG growth cone structure. J Neurosci 11:1597-1608.

Jankowska E, Jukes MGM, Lund S, Lundberg A (1967) The effect of DOPA on the spinal cord. 5. Reciprocal organization of pathways transmitting excitatory action to alpha motoneurons of flexors and extensors. Acta Physiol Scand 70:369-388.

Kapfhammer JP, Raper JA (1987) Collapse of growth cone structure on contact with specific neurites in culture. J Neurosci 7:201-212.
Kater SB, Mills LR (1991) Regulation of growth cone behavior by calcium. J Neurosci 11:891-899.

Keynes RJ, Cook GMW (1992) Repellent cues in axon guidance. Curr Opin Neurobiol 2:55-59.

Lankford KL, Letourneau PC (1989) Evidence that calcium may control neurite outgrowth by regulating the stability of actin filaments. $J$ Ccll Biol 109:1229-1243.

Letourneau PC (1975) Possible roles for cell-to-substratum adhesion in neuronal morphogenesis. Dev Biol 44:77-91.

Masuko S, Nakajima Y, Nakajima S, Yamaguchi K (1986) Noradrenergic neurons from the locus coeruleus in dissociated cell culture: culture methods, morphology, and electrophysiology. $J$ Neurosci 6:3229-3241.

McCleskey EW, Fox AP, Feldman D, Tsien RW (1986) Different types of calcium channels. J Exp Biol 124:177-190.

Miller RJ (1988) Calcium signaling in neurons. Trends Neurosci 11: $415-419$.

Moorman SJ, Hume RI (1990) Growth cones of chick sympathetic preganglionic neurons in vitro interact with other neurons in a cellspecific manner. J Neurosci 10:3158-3163.

Norton WT (1976) Isolation of myclin from ncrve tissue. In: Methods in enzymology, Vol 31 (Fleischer S, Packer L, eds), pp 435-444. New York: Academic.

Norton WT, Cammer W (1984) Isolation and characterization of myelin. In: Myelin (Morell P, ed), pp 147-195. New York: Plenum.

Olivera BM, Cruz LJ, de Santos V, LeCheminant GW, Griffin D, Zeikus R, McIntosh JM, Galyean R, Varga J, Gray WR (1987) Neuronal calcium channel antagonists. Discrimination between calcium channel subtypes using omega-conotoxin from Conus magnus venom. Biochemistry 26:2086-2090.

Plummer MR, Logothetis DE, Hess P (1989) Elementary properties and pharmacological sensitivities of calcium channels in mammalian peripheral neurons. Neuron 2:1453-1463.

Schnell L, Schwab ME (1990) Axonal regeneration in the rat spinal cord produced by an antibody against myelin-associated neurite growth inhibitors. Nature 343:269-272.

Tsien RW, Lipscombe D, Madison DV, Bley KR, Fox AP (1988) Multiple types of neuronal calcium channels and their selective modulation. Trends Neurosci 11:431-438.

Yaari Y, Hamon B, Lux HD (1987) Development of two types of calcium channels in cultured mammalian hippocampal neurons. Science 235:680-682. 